\title{
Sarcopenia, Cachexia and Aging: Diagnosis, Mechanisms and Therapeutic Options - A Mini-Review
}

\author{
Sumbul Ali ${ }^{a}$ Jose M. Garcia ${ }^{a}$ b \\ ${ }^{a}$ Division of Diabetes, Endocrinology and Metabolism, MCL, Center for Translational Research in Inflammatory \\ Diseases, Michael E. DeBakey Veterans Affairs Medical Center and Baylor College of Medicine, and ${ }^{b}$ Department of \\ Molecular and Cell Biology and Huffington Center on Aging, Baylor College of Medicine, Houston, Tex., USA
}

\section{Key Words}

Cachexia - Anorexia - Aging · Sarcopenia - Inflammation .

Ghrelin · Testosterone

\begin{abstract}
By the year 2050, individuals over the age of 65 years will comprise $20 \%$ of the US population. Loss of muscle mass and strength is common in this age group and it is associated with increased dependence, frailty and mortality. Sarcopenia, defined as the loss of muscle mass and function associated with aging, and cachexia, defined as weight loss due to an underlying illness, are muscle wasting disorders of particular relevance in the aging population, but they go largely unrecognized. In this review we highlight the common pathophysiological mechanisms underlying muscle loss in sarcopenia and cachexia, the factors unique to each condition and means of diagnosing and differentiating them clinically. Therapeutic options including exercise, nutritional therapy, androgens and growth hormone as well as their practical limitations are discussed. We also shed light on newer agents being developed as potential therapeutic options for wasting diseases.

(c) 2014 S. Karger AG, Basel
\end{abstract}

\section{Introduction}

During the 20th century, overall survival dramatically increased as a result of advances in medicine, particularly in the treatment of infectious and cardiovascular diseases. Consequently, at the beginning of the 21st century, we are looking at a rising percentage of an aging population. According to the US Census Bureau's projections, it is estimated that by the year 2050 the number of individuals over the age of 65 years will increase to approximately 80 million, comprising $20 \%$ of the US population, and $4.3 \%$ will be $\geq 85$ years of age [1]. Similar trends are recognized in other developed countries across the world. Ten percent of community-dwelling people aged 65 years or older require some assistance with activities of daily living. This number rises to $50 \%$ in those $>85$ years of age [1]. Given the disproportionate rise in the aged population, efforts to promote independence and decrease frailty in this demographic group are major challenges faced by the healthcare system looking ahead.

As the human body ages, there is a gradual decrease in muscle mass accompanied by gains in fat mass and abdominal circumference. This age-related loss of muscle mass and strength is often referred to as 'sarcopenia'. Weight loss due to an underlying disease is called 'ca-

\section{KARGER}

E-Mail karger@karger.com www.karger.com/ger
(C) 2014 S. Karger AG, Basel

0304-324X/14/0604-0294\$39.50/0
Jose M. Garcia, MD, PhD

Division of Diabetes, Endocrinology and Metabolism Michael E. DeBakey Veterans Affairs Medical Center 2002 Holcombe Boulevard, Building 109, Room 210, Houston, TX 77030 (USA) E-Mail jgarcia1@bcm.edu 
chexia', and it usually involves a loss of fat and muscle mass. This review reflects on the similarities and differences of the two conditions and the tools for managing them in the elderly.

\section{Mechanisms Regulating Skeletal Muscle Mass}

Muscle mass is determined by the balance between pathways favoring protein synthesis and breakdown. The best-defined anabolic pathway leading to protein synthesis in muscle involves activation of the serine/threonine kinase Akt, resulting in downstream amplification of mammalian target of rapamycin (mTOR), which leads to increased muscle protein synthesis [2]. Most muscle anabolic stimuli, especially insulin-like growth factor 1 (IGF1), and also branched-chain amino acids (e.g. leucine), exercise and testosterone upregulate this pathway [3]. Skeletal muscle atrophy involves muscle protein breakdown by activation of the ubiquitin proteasome pathway and caspases under transcriptional control of the transcription factors forkhead box $\mathrm{O}$ (Fox-O) and nuclear factor (NF)- $\mathrm{B}$ (fig. 1). Another important pathway leading to muscle atrophy is the myostatin pathway. Myostatin is a member of the transforming growth factor- $\beta$ family that is secreted by muscle cells, circulates in the blood and acts locally as a negative muscle mass regulator by downregulating the Akt/mTOR pathway and by decreasing the number of satellite cells [3]. The role of myostatin in muscle wasting in humans has not been well delineated, but it is emerging as a promising therapeutic target for muscle disorders. There is considerable crosscommunication between these synthetic and degradation pathways, and when the balance between these components is altered, muscle mass atrophy (as in sarcopenia and cachexia) or hypertrophy ensues (fig. 1). Other pathways that have been shown to contribute to cachexia and sarcopenia include an increase in muscle apoptosis $[4,5]$ and autophagy/lysosomal activity [6], and a decrease in mitochondrial function $[7,8]$ and satellite cells, which are essential for muscle repair $[9,10]$.

\section{Sarcopenia}

Sarcopenia (from Greek sarx, 'flesh', and penia, 'poverty') has been defined as the 'progressive loss of muscle mass and strength with a risk of adverse outcomes such as disability, poor quality of life and death' by the Special Interest Group of the European Sarcopenia Working
Group in 2010 [11]. The term is used specifically to denote loss of muscle mass and strength associated with aging and distinguishes muscle loss from aging from other causes such as immobility or neurological damage.

Sarcopenia is increasingly being recognized as a geriatric syndrome and a key public health issue. Starting at the age of 30 years, individuals lose $1-2 \%$ of muscle per year, and by the age of 80 years, $30 \%$ of the muscle mass is lost $[12,13]$. The prevalence of low muscle mass is estimated to be between 10 and $25 \%$ depending on the population and method used to identify sarcopenia. In octogenarians the prevalence increases to $50 \%$ [11]. Reduced muscle function is independently associated with increased risk of functional impairment, falls, disability and mortality in the elderly [14]. The direct cost attributed to sarcopenia in the year 2000 was $1.5 \%$ of the total healthcare expenditure. It is estimated that a $10 \%$ reduction in prevalence of sarcopenia would save USD 1.1 billion in health-related costs [15].

\section{Pathophysiologic Mechanisms Contributing to Sarcopenia}

Sarcopenia is characterized by atrophy of muscle fibers, especially type II fibers (fast), by a decreased number of motor units and by accumulation of fat within muscle [16]. There are multiple reasons for declining muscle mass with aging (fig. 2); however, their relative contribution to the process of normal aging has not been well characterized. Immobility seems to be an important driver of the pathophysiological changes leading to muscle loss. However, muscle loss can lead to immobility as well. There is also decreased synthetic capacity of the muscle with age, termed 'anabolic resistance' [17]. As mentioned earlier, testosterone, insulin and IGF-1 are potent activators of the Akt pathway, resulting in increased muscle protein synthesis and decreased degradation by inhibiting Fox-O (fig. 1). Testosterone also stimulates myoblasts, inhibits myostatin and increases satellite cells, which help in the repair of myocytes [18]. Aging is associated with lower testosterone levels, IGF-1 and insulin resistance, leading to decreased protein synthesis. Although there is an increase in circulating markers of inflammation such as interleukin (IL)-6 with advancing age, it is debatable whether such elevation is due to age alone or to underlying comorbidities that accompany old age [19]. Moreover, inflammatory pathways involving NF- $\kappa B$ are typically not activated in sarcopenia. Genetic potential, nutritional deficiencies and loss of lower motor neurons all play a role in tipping the balance toward muscle breakdown in the elderly $[11,20]$. Also, muscle autophagy is 
Fig. 1. Simplified cellular pathways for muscle protein synthesis and degradation. Blue: synthesis pathways. Red: proteolytic pathways. Dotted lines: pathways that are not well characterized. Anabolic signals activate the phosphatidylinositol 3-kinase (PI-3K)/Akt/mTOR pathway, resulting in protein synthesis. Inactivity and inflammatory cytokines result in activation of NF$\kappa \mathrm{B}-$ and Fox-O-mediated induction of genes, resulting in muscle atrophy. Fox-O activates transcription of ubiquitin proteasome ligases, resulting in protein degradation. PI-3K/Akt phosphorylates Fox-O, preventing its nuclear translocation and inhibiting its activity. Fox-O, when active, can inhibit the mTOR pathway. Also, mTOR pathway activation inhibits protein degradation by lysosomal caspases. Myostatin causes muscle atrophy via activating Fox-O and inhibiting PI-3K. BCAA = Branched-chain amino acids.
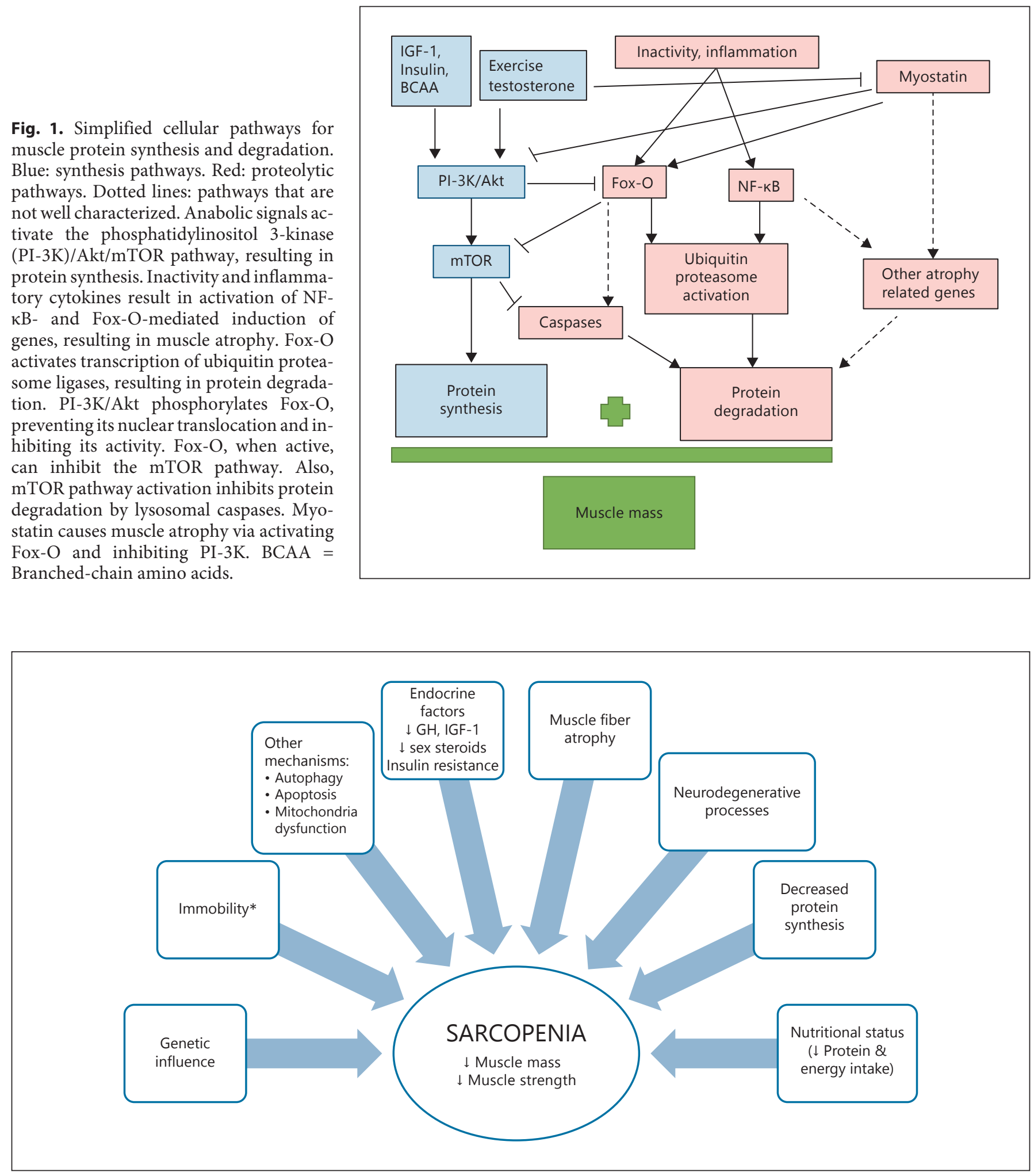

Fig. 2. Pathophysiology of sarcopenia. GH = Growth hormone. * Immobility may also be considered part of disuse atrophy rather than sarcopenia. 
impaired and apoptosis increased in animal models of sarcopenia. Interestingly, these changes are prevented by caloric restriction $[4,6]$. Lastly, mitochondrial function and content is decreased in aged muscles, and this is prevented by exercise [7].

\section{Diagnosis}

Sarcopenia is an underdiagnosed entity, partly due to lack of consensus regarding the optimal approach to diagnosis. Although targeted screening of at-risk patients has been proposed, this is not widely practiced (table 1 ). It has been recommended that elderly subjects who are chronically bedbound, are nonambulatory, have a history of recent significant weight loss and appear malnourished (including alcoholics), and those with chronic medical conditions associated with loss of muscle (e.g. diabetes and chronic heart, lung, kidney and liver disorders) should be assessed for the presence of muscle wasting [11], although some of these conditions are more likely to induce cachexia rather than sarcopenia.

Sarcopenia includes both a reduction in muscle mass as well as function. It has been suggested that the diagnosis can be made in subjects with muscle mass $\geq 2$ standard deviations (SD) below that of sex- and ethnicity-matched young adults along with slow walking speed $(<0.8 \mathrm{~m} / \mathrm{s}$ over $4 \mathrm{~m}$ ), or with reduced performance on any other commonly used test as part of a comprehensive geriatric assessment. In 2010 the European Working Group on Sarcopenia in Older People published guidelines in order to aid clinicians and researchers to assess muscle mass, which can vary depending on affordability and clinical settings (table 2) [21].

\section{Treatment}

Exercise

Both resistance and aerobic training have been shown to increase muscle strength and improve function. Progressive resistance training (PRT) is the best-studied form of exercise in this context and should be considered the primary intervention for sarcopenia. In PRT participants exercise their muscles against an increasing external force; it is performed at least 2-3 times a week for 8-12 weeks. The duration of sessions and number of exercises increase gradually over time based on each individual's capability and improvement. Yarasheski et al. [22] demonstrated that whole body muscle mass was increased by $1 \mathrm{~kg}$ in women and by $2.2 \mathrm{~kg}$ in men with 3 months of PRT. Fiatarone et al. [23] demonstrated not only improved muscle mass but also strength and gait speed with resistance training. A Cochrane review in 2009, looking at 121 trials,
Table 1. Sarcopenia screening

Targeted screening at:

Bedbound

Nonambulatory

Unable to rise from a sitting position unassisted

History of weight loss ( $>5 \%)$

Noted or reported decline in function/strength

History of recurrent falls

After hospitalization

Comorbidities associated with loss of muscle mass (e.g. diabetes mellitus, CHF, chronic kidney disease, COPD, rheumatoid arthritis)

Gait speed $<0.8 \mathrm{~m} / \mathrm{s}$ over $4 \mathrm{~m}$

$\mathrm{CHF}=$ Congestive heart failure; $\mathrm{COPD}=$ chronic obstructive pulmonary disease. Adapted from Fielding et al. [11].

concluded that PRT results in improved muscle strength as well as functional measures of physical performance including gait speed and getting up from a chair [24]. No intervention in the field so far has shown results superior to exercise - although a combination of exercise and other therapies could potentially surpass the benefits of exercise alone. Nevertheless, major barriers exist to the universal implementation of this simple tool. Communitydwelling elderly may lack access to and motivation for embarking on a strenuous exercise training program. PRT requires trained therapists and special equipment which are not routinely available to everyone. Other exercise options that are less intensive and do not require as many resources could be useful as well, although they may be less effective. Hence there remains a continued need for alternatives to address the growing problem of sarcopenia.

\section{Nutrition}

There is a considerable wealth of literature on nutritional interventions, including antioxidants, specific amino acids, combinations of amino acids, compounds like creatine and fatty acids, for the use of muscle building. However, the evidence is not conclusive and universal recommendations are not possible at this time. For a detailed overview refer to the review by Calvani et al. [25].

Of all the proposed dietary agents, protein supplements and vitamin D optimization seem to be the most promising. Supplementation of diets with additional calories, protein concentrates (such as whey) or, specifically, branched-chain amino acids (e.g. leucine) have been shown to have beneficial effects on mixed muscle protein synthesis in young adults. But these apparent benefits 
Table 2. Diagnostic criteria for sarcopenia

Reference range

Muscle mass

Anthropometry

(not recommended as it is very variable)

Bioimpedance analysis

Dual energy X-ray absorptiometry

Calf circumference $<31 \mathrm{~cm}$

Mid-upper arm circumference men: $<32 \mathrm{~cm}$; women: $<18 \mathrm{~cm}$

Predicted skeletal muscle mass (SM) equation (SM/height ${ }^{2}$; based on 2 SD below the mean of young adults in the study, $\mathrm{n}=200)-$ men: $8.87 \mathrm{~kg} / \mathrm{m}^{2}$; women: $6.42 \mathrm{~kg} / \mathrm{m}^{2}$

Skeletal Muscle Index using absolute muscle mass, not appendicular muscle mass [absolute muscle mass/ height ${ }^{2}$; based on statistical analysis of NHANES III data on older ( $\geq 60$ years) men and women] men: severe sarcopenia, $\leq 8.50 \mathrm{~kg} / \mathrm{m}^{2}$; moderate sarcopenia, $8.51-10.75 \mathrm{~kg} / \mathrm{m}^{2}$; normal muscle, $\geq 10.76 \mathrm{~kg} / \mathrm{m}^{2}$ women: severe sarcopenia, $\leq 5.75 \mathrm{~kg} / \mathrm{m}^{2}$; moderate sarcopenia, $5.76-6.75 \mathrm{~kg} / \mathrm{m}^{2}$; normal muscle, $\geq 6.76 \mathrm{~kg} / \mathrm{m}^{2}$

Skeletal muscle mass index $=$ appendicular skeletal muscle mass $/$ height $^{2}$ (2 SD below mean of young adults) men: $7.26 \mathrm{~kg} / \mathrm{m}^{2}$; women: $5.5 \mathrm{~kg} / \mathrm{m}^{2}$

\begin{tabular}{ll} 
Muscle strength & \\
Handgrip strength (using dynamometer) & Men: $<30$ \\
\hline Muscle function & \\
Short Physical Performance Battery & $\leq 8$ \\
Usual gait speed over $6 \mathrm{~m}$ & $<1 \mathrm{~m} / \mathrm{s}$ \\
Get-up-and-go test & $>10 \mathrm{~s}$
\end{tabular}

NHANES III = Third National Health and Nutrition Examination Survey. Adapted from: Cruz-Jentoft et al. $[21]$.

have not translated into improved functional performance or muscle mass in the elderly. Forty percent of the elderly do not meet the recommended $0.8 \mathrm{~g} / \mathrm{kg}$ protein intake requirement in their diet; and although experts propose at least a protein intake of $1.5 \mathrm{~g} / \mathrm{kg} /$ day comprising $15-20 \%$ of the total caloric intake for sarcopenic elderly [26], this may be difficult to achieve in certain scenarios.

There is ongoing controversy regarding the utility of supplementation with calcium and vitamin $\mathrm{D}$, despite considerable observational evidence linking low vitamin $\mathrm{D}$ levels to poor functional performance and frailty. A 2009 meta-analysis showed a 19\% risk reduction in falls in elderly people taking at least $700 \mathrm{IU}$ of supplemental vitamin D a day [27]. The Society on Sarcopenia, Cachexia and Wasting Diseases recommends checking 25-hydroxy-vitamin D levels and replacing, if low, in all sarcopenic patients [26].
Androgens/Selective Androgen Receptor Modulators Testosterone levels gradually decline with age. Approximately $20 \%$ of healthy men have testosterone levels in the hypogonadal range at the age of 60 years, and $50 \%$ after the age of 80 years [28]. Although testosterone has been shown to increase weight and muscle mass and to decrease fat mass in hypogonadal elderly men, studies of testosterone treatment in healthy populations are divisive. A study on 207 community-dwelling older males revealed that oral testosterone supplementation was beneficial in increasing lean body mass but did not demonstrate improved muscle function or strength [29]. On the other hand, Srinivas-Shankar et al. [30] demonstrated improved knee extensor functioning and physical functional improvement with transdermal testosterone supplementation in frail elderly. A 2010 trial of testosterone replacement in elderly men with a high burden of comorbidities and limited mobility was stopped early 
due to concerns of increased cardiovascular morbidity in the testosterone arm [31]. This group showed improvement in muscle strength and function with testosterone as compared with placebo. In summary, due to safety concerns, testosterone replacement or supplementation in the elderly frail population presently remains debatable, and guidelines recommend testosterone therapy for hypogonadal men after careful risk-benefit assessment [32].

Selective androgen receptor modulators (SARM) are agents with desirable androgenic effects in certain tissues (e.g. muscle and bone), but without effects on other organs like the prostate or skin, thereby limiting the adverse effects typically associated with androgens (prostate growth or androgenization). These agents have been shown to increase lean body mass and bone density in animal models. Recently, a phase II study of enobosarm in 120 healthy elderly showed an increase in lean body mass as well as improvement in stair climbing that was dose dependent. Enobosarm also decreased insulin resistance with a favorable safety profile [33]. These agents are not available on the market yet, and further studies are awaited to establish their role in muscle wasting disorders.

\section{Growth Hormone/IGF-1}

Growth hormone (GH), primarily through IGF-1, is a potent regulator of muscle growth and differentiation. $\mathrm{GH}$ administration to healthy older men increases lean body mass but induces no change in muscle functional parameters in addition to that seen with exercise. There was an increased incidence of adverse events, mainly fluid retention, edema, arthralgia and increased insulin resistance [34].

\section{Ghrelin Mimetics (GH Secretagogues)}

Ghrelin, an endogenous GH secretagogue (GHS) and appetite stimulant, has triggered much interest as a therapeutic option for wasting syndromes due to its action profile. Several studies involving ghrelin have demonstrated increased appetite, food intake and weight gain in healthy volunteers with no major adverse effects. Trials using oral GHS for ease of administration are also showing considerable promise. A randomized, blinded, placebo-controlled trial using the oral ghrelin mimetic MK677 for 1 year in healthy elderly men and women resulted in restoration of pulsatile GH secretion and IGF-1 levels to those seen in young healthy adults, and increased fatfree mass by $1.6 \mathrm{~kg}$ with no significant change in strength or function [35]. Another study using the GHS capromo- relin demonstrated not only increases in body weight and fat-free mass but also improved tandem gait, and by 12 months, stair climbing also improved [36]. More trials are needed to establish the efficacy and safety of these agents in the long-term treatment of sarcopenia.

\section{Other Agents}

Certain drugs that are known to improve functional performance and prognosis in heart failure patients, such as inhibitors of the renin-angiotensin system, are being investigated as agents for skeletal muscle preservation. Observational studies have shown improved skeletal muscle performance in subjects using these agents. In the Health $\mathrm{ABC}$ study there was an association seen between angiotensin-converting enzyme inhibitor (ACEI) users and lower-extremity muscle mass [37]. In the Women's Health and Aging Study, ACEI use was associated with a lower rate of decline in walking speed and lower-extremity muscle strength as compared with people who used ACEI intermittently or subjects taking other antihypertensives [38]. Prospective randomized studies assessing the effect of ACEI on measures of physical performance yielded mixed results, with one trial showing improvement in walking distance after 20 weeks of treatment, but others showing no change [39]. Inhibition of the reninangiotensin system leads to improved oxygen delivery to muscle tissue, and this is thought to be primarily responsible for the proposed beneficial effects of ACEI in this setting [40].

\section{Cachexia}

Cachexia (from the Greek cacos, 'bad', and hexis, 'having') is defined as a multifactorial syndrome characterized by severe body weight, fat and muscle loss due to an underlying illness [41]. Typically, it is associated with increased catabolism which cannot be reversed by mere nutritional support. Table 3 highlights the features distinguishing between cachexia and sarcopenia.

Between 10 and $40 \%$ of patients with chronic conditions including heart failure, chronic obstructive pulmonary disease (COPD), cancer, HIV, and renal and liver failure suffer from cachexia. This comprises more than 5 million people in the USA or approximately $2 \%$ of the population [42]. Table 4 lists the common causes of cachexia and its relevance in various diseases. Reliable estimates for cachexia in the elderly are not available, but the interplay between chronic illness and elements such as sarcopenia, malnutrition and immobility, all prevalent in 
Table 3. Differences between sarcopenia and cachexia

\begin{tabular}{lll}
\hline & Sarcopenia & Cachexia \\
\hline Definition & Muscle mass $<2$ SD of young healthy & Weight loss $>5 \%$ in \\
& population, decreased muscle function & 6 months \\
Mechanism & Aging & Pathologic \\
Comorbid condition & $+/-$ & +++ \\
Functional limitation & ++ & +++ \\
Inflammation & - & ++ \\
Fat mass & Increased & Decreased \\
Protein degradation & $-/+$ & +++ \\
Resting energy expenditure & Decreased & Increased \\
Anorexia & + & ++ \\
\hline
\end{tabular}

Table 4. Leading causes of cachexia

\begin{tabular}{|c|c|c|}
\hline Condition & $\begin{array}{l}\text { Prevalence } \\
\text { of cachexia }\end{array}$ & Impact of cachexia \\
\hline COPD & $25-35 \%$ & $\begin{array}{l}\text { Mortality } 10-15 \% / \text { year in cachectic patients; } \\
\text { impaired mobility and worsened response to treatment }\end{array}$ \\
\hline $\mathrm{CHF}$ & $16-42 \%$ & $\begin{array}{l}50 \% \text { mortality in } 18 \text { months as compared with } 17 \% \text { in } \\
\text { non-cachectic individuals in an unselected population }\end{array}$ \\
\hline Cancer & $\begin{array}{l}\text { Approx. } \\
30-60 \%\end{array}$ & $\begin{array}{l}\text { Up to } 20 \% \text { of deaths of cancer patients due to cachexia and its } \\
\text { associated morbidity; impacts mobility, quality of life and } \\
\text { treatment response }\end{array}$ \\
\hline $\begin{array}{l}\text { Advanced chronic } \\
\text { kidney disease }\end{array}$ & $30-60 \%$ & $20-30 \%$ mortality/year; blunted response to treatment \\
\hline Rheumatoid arthritis & $67 \%$ & Lean body mass loss with fat mass gain \\
\hline Chronic liver disease & Approx. 50\% & $\begin{array}{l}\text { Cachexia more common in males than in females with } \\
\text { cirrhosis }\end{array}$ \\
\hline
\end{tabular}

$\mathrm{CHF}=$ Congestive heart failure. Adapted from Morley et al. [43].

old age, makes this age group particularly vulnerable to cachexia. The importance of recognizing cachexia lies in the fact that it is an independent predictor of mortality, response to treatment as well as quality-of-life measures in different settings [42].

\section{Pathophysiologic Mechanisms Contributing to \\ Cachexia}

Inflammation is purported to play an important role in the pathogenesis of cachexia (fig. 3). Inflammatory cytokines including IL-1, IL- 6 and tumor necrosis factor- $\alpha$ induce myofibrillar breakdown by activation of the ubiquitin proteasome pathway, via NF- $\mathrm{kB}$-dependent and -independent mechanisms. As mentioned before, down- regulation of anabolic factors/pathways including IGF-1, androgens and satellite cell proliferation [10], and increases in catabolic pathways/processes such as apoptosis [5], autophagy [6], mitochondrial dysfunction $[7,8]$ and the myostatin pathway [3] all contribute to muscle mass and function loss in this setting.

Cytokine-mediated release of cortisol and adrenergic hormones can also lead to increased fat oxidation and fat atrophy, insulin resistance, hypermetabolism, anemia and fatigue. Numerous disease-, therapy- and patient-related factors such as pain, gastrointestinal obstruction, nausea, fatigue and depression also cause a paradoxical reduction in appetite in these patients, further aggravating their hypercatabolic state. 


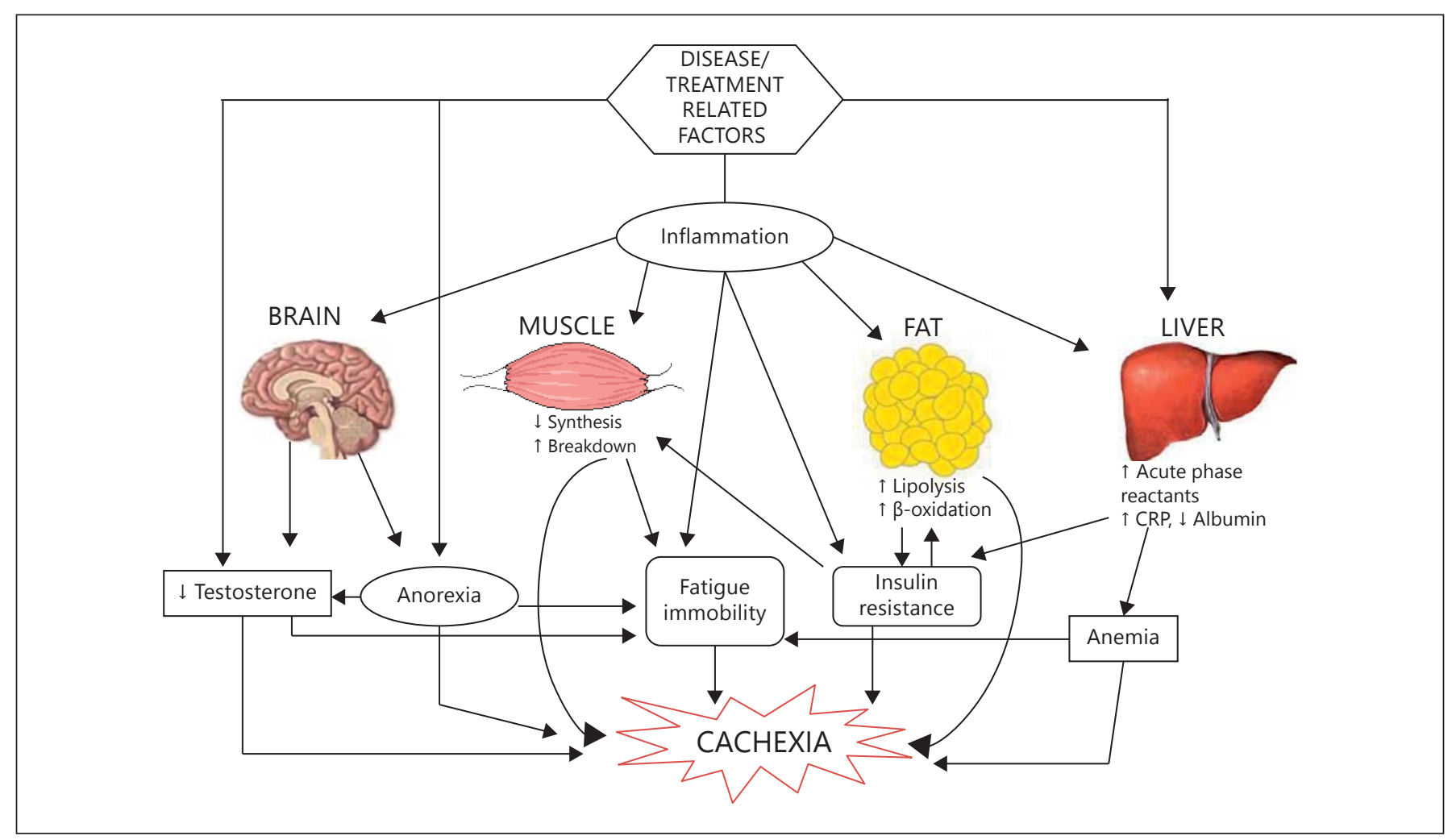

Fig. 3. Pathophysiology of cachexia. Various disease- or treatmentrelated factors lead to inflammation, hypogonadism, anorexia and insulin resistance, resulting in muscle and fat loss, anemia and fa- tigue, and ultimately leading to cachexia. These factors are interdependent and altered by disease type, stage and treatment. CRP = C-reactive protein.
The elderly, with their comorbidities, limited mobility, reduced nutrition, low IGF-1 and testosterone levels and low muscle mass, are especially vulnerable to cachexia even at earlier stages of the disease. Moreover, they are more likely to suffer from the consequences of increased dependence, increased utilization of care, poor response to therapy and worse prognosis as compared with the nonelderly population [43].

\section{Diagnosis}

There is no unanimous consensus about diagnosing cachexia. Most studies have used different weight loss cutoffs or symptoms to define cachexia. In 2008, Evans et al. [41] proposed a systematic approach to diagnosing cachexia for research as well as clinical purposes. This multidimensional model incorporates documenting weight loss of $>5 \%$ in the preceding year or BMI $<20$ along with the presence of any 3 of the following: fatigue, anorexia, decreased muscle strength, laboratory evidence of anemia ( $\mathrm{Hb}<12 \mathrm{~g} / \mathrm{dl})$, hypoalbuminemia $(<3.2 \mathrm{~g} / \mathrm{dl})$ or elevated markers of inflammation (e.g.
IL-6 or C-reactive protein) [41]. Further studies will be needed to validate this and other definitions in different settings.

\section{Treatment}

Despite a clear association of cachexia with adverse outcomes, there is currently no approved treatment for cachexia. However, there are some promising agents in trials underway and expected to be on the market in the future.

\section{Exercise and Nutrition}

Nutrition therapy coupled with exercise training is thought to be beneficial from a pathophysiological perspective in terms of decreasing protein breakdown and improving muscle function. Though cachectic patients may not feel motivated to exercise, evidence indicates that resistance training improves muscle strength and lean body mass, attenuates inflammatory markers and improves fatigue [44]. Cachexia is a hypercatabolic state and a diet containing $1.5 \mathrm{~g} / \mathrm{kg} /$ day of protein constituting 
$15-20 \%$ of total caloric intake is recommended to counter catabolism [45]. However, studies aimed at supplementing caloric intake or adding specific nutritional elements like whey protein supplements, branched-chain amino acids or creatine have not shown consistent benefit [46].

Appetite Stimulants

Appetite stimulants, including steroids, progestational agents such as megestrol acetate (MPA) and cannabinoids, are the oldest and best-studied drugs for cachexia, and hence maybe the only agents with which clinicians have some familiarity. Corticosteroids may result in subjective improvements in appetite and quality of life, but they are not recommended due to their side effects. MPA can increase appetite and body weight primarily through fat accrual, but side effects include venous thromboembolism, hypogonadism, adrenal insufficiency and possibly increased mortality in the elderly [47]. Cannabinoids like dronabinol are another option but are usually considered inferior in terms of efficacy as compared with steroidal agents [48].

\section{Androgens/SARM}

Oxandrolone, an oral synthetic testosterone derivative with minimal androgenic effects, has been approved for use in men and women with weight loss associated with catabolic conditions including surgery, burns and chronic infections. It has been shown to increase lean body mass and body weight in HIV- and COPD-related weight loss. It is, in general, well tolerated, but may cause hypogonadism in men [49]. SARM are tissue-specific nonsteroidal androgenic agents expected to have minimal androgenic and prostatic side effects and greater anabolic potency compared with testosterone. Recently, a phase II, randomized controlled trial of enobosarm in 159 patients with cancer and $2 \%$ weight loss showed significant weight gain when compared with placebo (median lean body mass gain: $1-1.5 \mathrm{~kg}$ ) with up to 113 days of treatment. No adverse effects related to the drug were reported [50]. Further phase III studies are taking place in cancer-cachexia to test the safety and efficacy of this agent.

\section{Growth Hormone}

Recombinant GH has shown consistently favorable results in various catabolic states including AIDS, congestive heart failure (CHF), COPD and hemodialysis as well as in postsurgical patients. Recombinant $\mathrm{GH}$ has been approved by the US Food and Drug Administration for the treatment of HIV wasting syndrome, pediatric chronic kidney disease and parenteral nutrition-dependent shortbowel patients to treat cachexia. However, it is costly, requires daily subcutaneous injections, and its side effects include arthralgia, edema, insulin resistance, paresthesia and sodium retention [34]. It is also contraindicated in individuals with active tumors, although the evidence linking $\mathrm{GH}$ and cancer is weak.

\section{Ghrelin and Ghrelin Mimetics}

Ghrelin as an infusion, or its synthetic analogues as oral agents, have been studied in weight loss in conditions including cancer, $\mathrm{CHF}$, end-stage renal disease, COPD and anorexia nervosa. Acylated ghrelin infusions have been shown to increase appetite and food intake in healthy subjects and in cancer, COPD and CHF patients. Ghrelin demonstrated an excellent short-term safety profile with no major adverse effects reported. Ghrelin mimetics (also known as GHS) are orally administered, small molecules with a longer half-life, making them easier to use in clinical settings. In a randomized, double-blinded crossover study, 16 patients with cancer cachexia were randomized to receive placebo or the GHS anamorelin for 3 days. Anamorelin significantly increased body weight by $0.77 \mathrm{~kg}$ as well as appetite [51]. Adverse events were mild and included hyperglycemia, nausea and dizziness. Ghrelin mimetics show considerable potential as a future therapy against cachexia. Larger studies are ongoing to test the safety and efficacy of this intervention in cancer subjects.

Anti-Inflammatory Agents (Nonsteroidal

Anti-Inflammatory Drugs, Omega-3 Fatty Acids, Thalidomide)

Since inflammation is an important underlying mechanism for cachexia, drugs targeting inflammatory cytokines are of particular interest to the field, but none have shown beneficial effects consistently. Studies looking at $\omega-3$ fatty acids like eicosapentaenoic acid, both nonselective and selective COX inhibitors, anti-tumor necrosis factor agents and thalidomide have reported variable efficacy and inconsistent results [40]. Thalidomide, an immunomodulatory, antineoplastic and anti-inflammatory agent, seemed to ameliorate the weight loss seen in certain cancers, but a Cochrane review conducted in 2012 concluded that there is a paucity of evidence to recommend thalidomide for such use [52]. One randomized controlled trial evaluating a multimodal cachexia treatment approach showed a benefit of using thalidomide, MPA, eicosapentaenoic acid, L-carnitine and nutritional support together, but there was significant heterogeneity between groups, preventing any meaningful conclusions 
about each individual arm. These studies suggest that since cachexia is a multifactorial entity, an approach targeting different underlying mechanisms including inflammation, appetite stimulation and muscle anabolic agents may prove more efficacious than targeting inflammation alone.

\section{Beta Blockers}

Beta blockers may also have a beneficial effect on preserving body weight as they inhibit catecholamine-dependent lipolysis, decrease resting energy expenditure and induce vasodilation and enhanced oxygenation. In a rat model of cachexia they have shown improved survival and decreased weight loss [40]. Further research is needed to establish the role of these agents in muscle preservation in the elderly.

\section{Future Therapies}

Melanocortin Receptor Inhibition

Mutations in the melanocortin 4 receptor, a receptor for a-melanocyte-stimulating hormone, have been linked to obesity. The $\alpha$-melanocyte-stimulating hormone/melanocortin 4 receptor binding leads to widespread effects, ultimately culminating in appetite control and decreased body mass, while antagonism of this pathway leads to increased appetite and weight gain. These compounds have shown promising results in mouse models of cachexia, and trials in human subjects are awaited [53].

\section{Myostatin Inhibitors}

Myostatin inhibits muscle protein synthesis and promotes fibrosis, while myostatin inhibition leads to muscle hypertrophy. Hence, ways to inhibit its activity are of immense interest in the prevention of muscle loss. Several agents are in development, including hormones such as follistatin (a natural myostatin-binding protein), recombinant myostatin antibodies and soluble activin type IIB receptors (myostatin binds to activin type I, IIA and IIB receptors for its action), all of which are mechanistic myostatin antagonists. Trials are underway to assess their effects on muscle disorders such as wasting or muscular dystrophies [54].

\section{Anti-IL-6 Antibodies}

In preclinical and phase I and II studies of non-smallcell lung cancer, a monoclonal antibody to IL-6, ALD518, seemed to be of benefit in ameliorating cancer-related cachexia and anemia in humans [55]. Further studies are needed to confirm this observation.

\section{Conclusion}

There is ample evidence showing that weight and muscle loss are associated with frailty, loss of independence, poor prognosis and increased mortality. The elderly are particularly prone to the spectrum of wasting diseases and their unfavorable consequences. Despite this, we fail to identify sarcopenia and cachexia in the majority of patients until the disease is advanced. Currently, we have limited options to counter the effects of muscle loss as part of aging or a disease process except for lifestyle therapies like healthy nutrition and exercise training. Nonetheless, the future looks bright with some promising new therapies on the horizon.

\section{Acknowledgements}

J.M.G. receives research support from the Department of Veterans Affairs (MERIT grants: I01-BX000507 and I01-CX000174) and the National Institute on Aging (T32AG000183 and AG040583).

\section{Disclosure Statement}

J.M.G. is a consultant for and receives research support from Æterna Zentaris Inc. and Helsinn Therapeutics Inc.

\section{References}

1 US Census Bureau: Table 2. Projections of the population by selected age groups and sex for the United States: 2010 to 2050 (NP2008-T2); in Population Division, US Census Bureau. Washington, US Census Bureau, 2008.

$\checkmark 2$ Bodine SC, Stitt TN, Gonzalez M, Kline WO, Stover GL, Bauerlein R, Zlotchenko E, Scrimgeour A, Lawrence JC, Glass DJ, Yancopoulos GD: Akt/mTOR pathway is a crucial regulator of skeletal muscle hypertrophy and can prevent muscle atrophy in vivo. Nat Cell Biol 2001;3:1014-1019.

-3 Sandri M: Signaling in muscle atrophy and hypertrophy. Physiology (Bethesda) 2008;23: 160-170.

4 Marzetti E, Carter CS, Wohlgemuth SE, Lees HA, Giovannini S, Anderson B, Quinn LS, Leeuwenburgh C: Changes in IL-15 expres- sion and death-receptor apoptotic signaling in rat gastrocnemius muscle with aging and life-long calorie restriction. Mech Ageing Dev 2009;130:272-280.

5 Busquets S, Deans C, Figueras M, MooreCarrasco R, Lopez-Soriano FJ, Fearon KC, Argiles JM: Apoptosis is present in skeletal muscle of cachectic gastro-intestinal cancer patients. Clin Nutr 2007;26:614-618. 
6 Penna F, Costamagna D, Pin F, Camperi A, Fanzani A, Chiarpotto EM, Cavallini G, Bonelli G, Baccino FM, Costelli P: Autophagic degradation contributes to muscle wasting in cancer cachexia. Am J Pathol 2013;182: 1367-1378.

7 Kang C, Chung E, Diffee G, Ji LL: Exercise training attenuates aging-associated mitochondrial dysfunction in rat skeletal muscle: role of PGC-1 $\alpha$. Exp Gerontol 2013;48:13431350.

-8 Padrao AI, Oliveira P, Vitorino R, Colaco B, Pires MJ, Marquez M, Castellanos E, Neuparth MJ, Teixeira C, Costa C, Moreira-Goncalves D, Cabral S, Duarte JA, Santos LL, Amado F, Ferreira R: Bladder cancer-induced skeletal muscle wasting: disclosing the role of mitochondria plasticity. Int J Biochem Cell Biol 2013;45:1399-1409.

$\checkmark 9$ Reed SA, Sandesara PB, Senf SM, Judge AR: Inhibition of FoxO transcriptional activity prevents muscle fiber atrophy during cachexia and induces hypertrophy. FASEB J 2012;26: 987-1000.

10 Verdijk LB, Koopman R, Schaart G, Meijer K, Savelberg HH, van Loon LJ: Satellite cell content is specifically reduced in type II skeletal muscle fibers in the elderly. Am J Physiol Endocrinol Metab 2007;292:E151E157.

-11 Fielding RA, Vellas B, Evans WJ, Bhasin S, Morley JE, Newman AB, Abellan van Kan G, Andrieu S, Bauer J, Breuille D, Cederholm T, Chandler J, de Meynard C, Donini L, Harris T, Kannt A, Keime Guibert F, Onder G, Papanicolaou D, Rolland Y, Rooks D, Sieber C, Souhami E, Verlaan S, Zamboni M: Sarcopenia: an undiagnosed condition in older adults. Current consensus definition: prevalence, etiology, and consequences. International Working Group on Sarcopenia. J Am Med Dir Assoc 2011;12: 249-256.

12 Frontera WR, Hughes VA, Fielding RA, Fiatarone MA, Evans WJ, Roubenoff R: Aging of skeletal muscle: a 12-yr longitudinal study. J Appl Physiol 2000;88:1321-1326.

$\checkmark 13$ Lexell J: Human aging, muscle mass, and fiber type composition. J Gerontol A Biol Sci Med Sci 1995;50(spec No):11-16.

14 Janssen I, Heymsfield SB, Ross R: Low relative skeletal muscle mass (sarcopenia) in older persons is associated with functional impairment and physical disability. J Am Geriatr Soc 2002;50:889-896

-15 Janssen I, Shepard DS, Katzmarzyk PT, Roubenoff R: The healthcare costs of sarcopenia in the United States. J Am Geriatr Soc 2004;52:80-85.

16 Muscaritoli M, Anker SD, Argiles J, Aversa Z, Bauer JM, Biolo G, Boirie Y, Bosaeus I, Cederholm T, Costelli P, Fearon KC, Laviano A, Maggio M, Rossi Fanelli F, Schneider SM, Schols A, Sieber CC: Consensus definition of sarcopenia, cachexia and pre-cachexia: joint document elaborated by special interest groups (SIG) 'Cachexia-Anorexia in Chronic
Wasting Diseases' and 'Nutrition in Geriatrics'. Clin Nutr 2010;29:154-159.

17 Drummond MJ, Miyazaki M, Dreyer HC, Pennings B, Dhanani S, Volpi E, Esser KA, Rasmussen BB: Expression of growth-related genes in young and older human skeletal muscle following an acute stimulation of protein synthesis. J Appl Physiol 2009;106:14031411.

18 Bhasin S, Taylor WE, Singh R, Artaza J, Sinha-Hikim I, Jasuja R, Choi H, GonzalezCadavid NF: The mechanisms of androgen effects on body composition: mesenchymal pluripotent cell as the target of androgen action. J Gerontol A Biol Sci Med Sci 2003; 58:M1103-M1110.

19 Cohen HJ, Pieper CF, Harris T, Rao KM, Currie MS: The association of plasma IL-6 levels with functional disability in communitydwelling elderly. J Gerontol A Biol Sci Med Sci 1997;52:M201-M208.

20 Brown WF: A method for estimating the number of motor units in thenar muscles and the changes in motor unit count with ageing. J Neurol Neurosurg Psychiatry 1972;35:845852.

21 Cruz-Jentoft AJ, Baeyens JP, Bauer JM, Boirie Y, Cederholm T, Landi F, Martin FC, Michel JP, Rolland Y, Schneider SM, Topinková E, Vandewoude M, Zamboni M; European Working Group on Sarcopenia in Older People: Sarcopenia: European consensus on definition and diagnosis - report of the European Working Group on Sarcopenia in Older People. Age Ageing 2010;39:412-423.

22 Yarasheski KE, Pak-Loduca J, Hasten DL, Obert KA, Brown MB, Sinacore DR: Resistance exercise training increases mixed muscle protein synthesis rate in frail women and men $\geq 76$ yr old. Am J Physiol 1999;277:E118 E125.

23 Fiatarone MA, Marks EC, Ryan ND, Meredith CN, Lipsitz LA, Evans WJ: High-intensity strength training in nonagenarians: effects on skeletal muscle. JAMA 1990;263:30293034.

24 Liu CJ, Latham NK: Progressive resistance strength training for improving physical function in older adults. Cochrane Database Syst Rev 2009;3:CD002759.

25 Calvani R, Miccheli A, Landi F, Bossola M, Cesari M, Leeuwenburgh C, Sieber CC, Bernabei R, Marzetti E: Current nutritional recommendations and novel dietary strategies to manage sarcopenia. J Frailty Aging 2013;2: $38-53$.

26 Morley JE, Argiles JM, Evans WJ, Bhasin S, Cella D, Deutz NE, Doehner W, Fearon KC, Ferrucci L, Hellerstein MK, Kalantar-Zadeh K, Lochs H, MacDonald N, Mulligan K, Muscaritoli M, Ponikowski P, Posthauer ME, Rossi Fanelli F, Schambelan M, Schols AM, Schuster MW, Anker SD; Society for Sarcopenia, Cachexia, and Wasting Disease: Nutritional recommendations for the management of sarcopenia. J Am Med Dir Assoc 2010;11: 391-396.
27 Bischoff-Ferrari HA, Dawson-Hughes B, Staehelin HB, Orav JE, Stuck AE, Theiler R, Wong JB, Egli A, Kiel DP, Henschkowski J: Fall prevention with supplemental and active forms of vitamin D: a meta-analysis of randomised controlled trials. BMJ 2009; 339:b3692.

28 Morley JE, Kaiser FE, Perry HM 3rd, Patrick P, Morley PM, Stauber PM, Vellas B, Baumgartner RN, Garry PJ: Longitudinal changes in testosterone, luteinizing hormone, and follicle-stimulating hormone in healthy older men. Metabolism 1997;46:410413.

29 Emmelot-Vonk MH, Verhaar HJ, Nakhai Pour HR, Aleman A, Lock TM, Bosch JL, Grobbee DE, van der Schouw YT: Effect of testosterone supplementation on functional mobility, cognition, and other parameters in older men: a randomized controlled trial. JAMA 2008;299:39-52.

30 Srinivas-Shankar U, Roberts SA, Connolly MJ, O'Connell MD, Adams JE, Oldham JA. $\mathrm{Wu}$ FC: Effects of testosterone on muscle strength, physical function, body composition, and quality of life in intermediate-frail and frail elderly men: a randomized, doubleblind, placebo-controlled study. J Clin Endocrinol Metab 2010;95:639-650.

31 Basaria S, Coviello AD, Travison TG, Storer TW, Farwell WR, Jette AM, Eder R, Tennstedt S, Ulloor J, Zhang A, Choong K, Lakshman KM, Mazer NA, Miciek R, Krasnoff J, Elmi A, Knapp PE, Brooks B, Appleman E, Aggarwal S, Bhasin G, Hede-Brierley L, Bhatia A, Collins L, LeBrasseur N, Fiore LD, Bhasin S: Adverse events associated with testosterone administration. N Engl J Med 2010;363:109122

32 Bhasin S, Cunningham GR, Hayes FJ, Matsumoto AM, Snyder PJ, Swerdloff RS, Montori VM, Task Force Endocrine Society: Testosterone therapy in men with androgen deficiency syndromes: an Endocrine Society clinical practice guideline. J Clin Endocrinol Metab 2010;95:2536-2559.

33 Dalton JT, Barnette KG, Bohl CE, Hancock ML, Rodriguez D, Dodson ST, Morton RA, Steiner MS: The selective androgen receptor modulator GTx-024 (enobosarm) improves lean body mass and physical function in healthy elderly men and postmenopausal women: results of a double-blind, placebocontrolled phase II trial. J Cachexia Sarcopenia Muscle 2011;2:153-161.

34 Giannoulis MG, Martin FC, Nair KS, Umpleby AM, Sonksen P: Hormone replacement therapy and physical function in healthy older men: time to talk hormones? Endocr Rev 2012;33:314-377.

35 Nass R, Pezzoli SS, Oliveri MC, Patrie JT, Harrell FE Jr, Clasey JL, Heymsfield SB, Bach MA, Vance ML, Thorner MO: Effects of an oral ghrelin mimetic on body composition and clinical outcomes in healthy older adults: a randomized trial. Ann Intern Med 2008;149: 601-611. 
-36 White HK, Petrie CD, Landschulz W, MacLean D, Taylor A, Lyles K, Wei JY, Hoffman AR, Salvatori R, Ettinger MP, Morey MC, Blackman MR, Merriam GR; Capromorelin Study Group: Effects of an oral growth hormone secretagogue in older adults. J Clin Endocrinol Metab 2009;94:1198-1206.

37 di Bari M, van de Poll-Franse LV, Onder G, Kritchevsky SB, Newman A, Harris TB, Williamson JD, Marchionni N, Pahor M: Antihypertensive medications and differences in muscle mass in older persons: the Health, Aging and Body Composition Study. J Am Geriatr Soc 2004;52:961-966.

38 Onder G, Penninx BW, Balkrishnan R, Fried LP, Chaves PH, Williamson J, Carter C, di Bari M, Guralnik JM, Pahor M: Relation between use of angiotensin-converting enzyme inhibitors and muscle strength and physical function in older women: an observational study. Lancet 2002;359:926-930.

- 39 Sumukadas D, Witham MD, Struthers AD, McMurdo ME: Effect of perindopril on physical function in elderly people with functional impairment: a randomized controlled trial. CMAJ 2007;177:867-874.

40 Rolland Y, Onder G, Morley JE, GilletteGuyonet S, Abellan van Kan G, Vellas B: Current and future pharmacologic treatment of sarcopenia. Clin Geriatr Med 2011; 27:423-447.
41 Evans WJ, Morley JE, Argiles J, Bales C, Baracos V, Guttridge D, Jatoi A, Kalantar-Zadeh K, Lochs H, Mantovani G, Marks D, Mitch WE, Muscaritoli M, Najand A, Ponikowski P, Rossi Fanelli F, Schambelan M, Schols A, Schuster M, Thomas D, Wolfe R, Anker SD: Cachexia: a new definition. Clin Nutr 2008; 27:793-799.

42 Tan BH, Fearon KC: Cachexia: prevalence and impact in medicine. Curr Opin Clin Nutr Metab Care 2008;11:400-407.

43 Morley JE, Thomas DR, Wilson MM: Cachexia: pathophysiology and clinical relevance. Am J Clin Nutr 2006;83:735-743.

44 Little JP, Phillips SM: Resistance exercise and nutrition to counteract muscle wasting. Appl Physiol Nutr Metab 2009;34:817-828.

45 op den Kamp CM, Langen RC, Haegens A, Schols AM: Muscle atrophy in cachexia: can dietary protein tip the balance? Curr Opin Clin Nutr Metab Care 2009;12:611-616.

46 Baldwin C, Spiro A, Ahern R, Emery PW: Oral nutritional interventions in malnourished patients with cancer: a systematic review and meta-analysis. J Natl Cancer Inst 2012;104:371-385.

47 Ruiz Garcia V, López-Briz E, Carbonell Sanchis R, Gonzalvez Perales JL, Bort-Marti S: Megestrol acetate for treatment of anorexiacachexia syndrome. Cochrane Database Syst Rev 2013;3:CD004310.

48 Jatoi A, Windschitl HE, Loprinzi CL, Sloan JA, Dakhil SR, Mailliard JA, Pundaleeka S, Kardinal CG, Fitch TR, Krook JE, Novotny PJ, Christensen B: Dronabinol versus megestrol acetate versus combination therapy for cancer-associated anorexia: a North Central Cancer Treatment Group study. J Clin Oncol 2002;20:567-573.
49 Orr R, Fiatarone Singh M: The anabolic androgenic steroid oxandrolone in the treatment of wasting and catabolic disorders: review of efficacy and safety. Drugs 2004;64: 725-750.

50 Dobs AS, Boccia RV, Croot CC, Gabrail NY, Dalton JT, Hancock ML, Johnston MA, Steiner MS: Effects of enobosarm on muscle wasting and physical function in patients with cancer: a double-blind, randomised controlled phase 2 trial. Lancet Oncol 2013;14: 335-345.

51 Garcia JM, Friend J, Allen S: Therapeutic potential of anamorelin, a novel oral ghrelin mimetic, in patients with cancer-related cachexia: a multicenter, randomized, double-blind, crossover, pilot study. Support Care Cancer 2013;21:129-137.

52 Reid J, Mills M, Cantwell M, Cardwell CR, Murray LJ, Donnelly M: Thalidomide for managing cancer cachexia. Cochrane Database Syst Rev 2012;4:CD008664.

53 DeBoer MD: Update on melanocortin interventions for cachexia: progress toward clinical application. Nutrition 2010;26:146-151.

54 Tsuchida K: Targeting myostatin for therapies against muscle-wasting disorders. Curr Opin Drug Discov Devel 2008;11:487-494.

55 Bayliss TJ, Smith JT, Schuster M, Dragnev $\mathrm{KH}$, Rigas JR: A humanized anti-IL-6 antibody (ALD518) in non-small cell lung cancer. Expert Opin Biol Ther 2011;11:1663-1668. 